\title{
Attaining Status at the Expense of Likeability: Pilfering Power Through Conversational Interruption
}

Article in Journal of Nonverbal Behavior · December 2008

DOI: 10.1007/s10919-008-0054-x

CITATIONS

20

1 author:

\section{Sally D Farley}

University of Baltimore

18 PUBLICATIONS 157 CITATIONS

SEE PROFILE
READS

143

Some of the authors of this publication are also working on these related projects: 


\title{
Attaining Status at the Expense of Likeability: Pilfering Power Through Conversational Interruption
}

\author{
Sally D. Farley
}

Published online: 22 July 2008

(C) Springer Science+Business Media, LLC 2008

\begin{abstract}
Do status expectations affect how we interpret interruption in conversation? Two experiments examined how interrupters and their targets are perceived in same- and mixed-gender dyads. In Experiment 1, participants listened to a brief audiotaped conversation in which one person interrupted the other five times. In Experiment 2, four confederates (two men and two women) systematically interrupted naïve participants while discussing an article. In general, interrupters gained in status and targets of interruption lost status. In addition, participants who were interrupted rated themselves as less influential than those who were not interrupted. As expected, interrupters, especially female interrupters, were liked less than those who did not interrupt. Theoretical implications are discussed.
\end{abstract}

Keywords Nonverbal behavior · Power - Status · Interruption · Group dynamics

The relationships between various nonverbal behaviors (NVBs) and dimensions of power (status, dominance) have been of great interest to psychologists, sociologists, and communication researchers alike. Hall et al. (2005), in their recent meta-analysis examining these relationships, found that participants assigned higher power ratings to others who smiled less, gazed more, nodded more, touched others more, touched themselves less, gestured more, talked louder and faster, and interrupted more than those who did not. Although beliefs about the relationship between power and nonverbal behavior (NVB) were stronger than actual differences (Hall et al.), social psychologists emphasize the importance of our perceptions in influencing others' behavior. If some believe that

This paper is based upon my doctoral dissertation, which was conducted at Virginia Commonwealth University. I would like to thank Mark Stasson, Amie Ashcraft, Susan Hughes and Jon Farley for critiquing versions of this manuscript.

S. D. Farley $(\bowtie)$

Division of Applied Behavioral Sciences, University of Baltimore, 1420 N. Charles St.,

Baltimore, MD 21201, USA

e-mail: sfarley@ubalt.edu 
gesturing frequently signifies greater power (it actually does not) and they act on the basis of this expectancy (deferring to the "powerful other"), then the resulting group dynamic could become self-fulfilling. Perhaps some of the actual differences in NVB can be attributed to consensually shared expectations about what signifies power in our society and how those expectations help shape status differentials.

While the polysemous nature of nonverbal behaviors complicates our ability to ascribe meaning to them (Hall 2006; Tannen 1993), many NVBs are linked with power. Indeed, theorists have argued that NVBs, along with other linguistic strategies, both reflect and maintain status differentials in interaction (Ridgeway et al. 1985; See also Fisek et al. 1991; Ridgeway 1982). Smith-Lovin and Brody (1989) wrote, "Language use... reflects the hierarchical social structure outside of the group, while simultaneously providing the means through which that inequality is maintained" (p. 424). Because certain behaviors, such as gaze duration and speaking volume, are believed to be associated with those who possess higher status, the cues themselves provide information as to the competence of individuals (Ridgeway et al. 1985; Ridgeway and Berger 1986). Consequently, one would predict that interruption, due to its association with higher status positions, would confer upon the interrupter increased status. The central focus of the present research is to determine the status-organizing effects of interruption in conversation.

Interruptions, which are associated with both perceived and actual power (Hall et al. 2005), have a history of inconsistent operationalization. While back-channel utterances (such as "uh-huh") and unintentional overlaps are sometimes categorized as interruptions (Dabbs and Ruback 1984), these behaviors may reflect attentiveness and solidarity instead of a desire to dominate (Tannen 1993). Researchers have described three non mutuallyexclusive categories of interruption which are related to dominance: deep interruptions in which one interrupts with a change of topic (LaFrance 1992), successful interruptions in which one causes the speaker to stop talking (Anderson and Leaper 1998; Beattie 1981; Roger and Nesshoever 1987; West and Zimmerman 1983), and intrusive interruptions (which may or may not be successful), which intrude into the crux of another person's point (James and Clarke 1993). I will return to these distinctions when defining interruption for these experiments.

Questions about gender inevitably surface in discussions of the relationship between power and NVB. Most of the research addressing gender differences in interruption has concluded that men engage in interruption (especially intrusive interruption) more than women do (Anderson and Leaper 1998; Kennedy and Camden 1983), and women are more frequent targets of interruption than are men (James and Clarke 1993; Smith-Lovin and Brody 1989). In addition, men interrupt women significantly more than other men (James and Clarke 1993; Smith-Lovin and Brody 1989).

Although some NVBs like interruption reveal parallel gender and status effects (Aries 1998), Henley's (1977, 1995) assumption that gender differences are caused by underlying status differences has received mixed empirical support. Hall et al. (2005) noted that some behaviors associated with higher power are more characteristic of men's behavior (i.e., interruptions), but others associated with higher power are more common in women (i.e., better encoding skills).

Expectation States Theory (EST) offers an account of how gender and status interact in small groups (Berger 1974). Behaviors like interruption which are perceived to be dominance-related are implicated in the maintenance of status differentials in interaction. Those possessing greater status are encouraged to engage in powerful behavior, and should consequently receive more positive evaluations for these behaviors, including interruption (Berger et al. 1972; Wagner and Berger 1997). Furthermore, an interruption by a lower 
status person will be construed as an illegitimate violation of expectancy (Ridgeway 1987). Lower status individuals who behave assertively are viewed negatively unless they possess relevant expertise on the task (Ridgeway 1982; Wagner and Berger 1997). While relevant skills and expertise function as specific status characteristics, appropriately guiding the allocation of status, gender operates as a diffuse status characteristic. Gender becomes salient in mixed-sex groups, guiding performance expectations such that women are expected to behave more submissively. Women who interrupt others are evaluated harshly because not only do they violate the social order of prescriptive norms (Floyd et al. 1999; LaFrance 1992), they violate our intuitive assumptions about the status hierarchy (Wagner and Berger 1997).

Another theoretical angle from which to view interruption is Expectancy Violations Theory (EVT), which focuses more explicitly on nonverbal behaviors as expectancy violations (Burgoon and Dunbar 2006). EVT holds that nonverbal behavior violations (such as personal space invasion) increase arousal, divert attention away from the content of the interaction and toward the source of the violation (Burgoon and Ebesu Hubbard 2005). Our perceptions of the violation are colored by characteristics of the communicator, especially when the behavior's meaning is ambiguous (Burgoon 1993). Specifically, communicators who are evaluated more positively (for example, those who are well-liked or who have higher status) have more freedom to violate expectations about prescriptive nonverbal behavior (Burgoon 1993; Burgoon and Dunbar 2006; Burgoon and Ebesu Hubbard 2005). When there is a power differential present, “...superiors often have the 'right' to initiate touch, to interrupt, and to control the flow of conversation whereas we would consider these behaviors inappropriate for a subordinate," (Floyd et al. 1999, p. 439). To the extent that gender is interpreted as a status cue, according to EVT, interruption should increase evaluations for men, but hurt evaluations for women.

A few experimental studies investigating how interrupters and their targets are perceived have manipulated interruption through audiotapes (Chambliss and Feeny 1992; LaFrance 1992; Robinson and Reis 1989). Robinson and Reis created 4-min audiotapes in which one person interrupted the other 10 times. Results showed that participants evaluated both interrupters and their targets differently than controls, but gender did not interact with condition. Regardless of interrupter gender, interrupters were perceived as more assertive and masculine than non-interrupters, and targets were viewed as less assertive and masculine than their non-interrupted controls.

Two other experiments found that gender composition was relevant (Chambliss and Feeny 1992; LaFrance 1992). LaFrance's work indicated that interrupters (especially women) were viewed as more confrontational, assertive and disrespectful than those they interrupted, even though the audiotape was $45 \mathrm{~s}$ long and included just two interruptions. Chambliss and Feeny limited their study to only cross-gender interruptions, and found that female interrupters were viewed as more assertive than male interrupters, a finding consistent with the predictions of EST and EVT. Interestingly, these studies illustrate that the consequences of interruption can be both positive (i.e., being viewed as assertive) and negative (i.e., being perceived as rude), especially for female interrupters.

The present research involved two experiments that examined how interrupters and their targets are perceived and included gender as a variable. In Experiment 1, participants listened to an audiotaped conversation in which one person interrupted another person five times. Then participants evaluated both partners on dimensions of status and likeability. In Experiment 2, trained confederates interrupted naïve participants eight times during a discussion. Participants in this experiment evaluated confederates on the same dimensions as in Experiment 1, and also rated their own competence and influence. 
The research presented here attempted to clarify inconsistencies in previous literature, in addition to providing unique contributions. First, while previous research has established that interruption affects our impressions, the relatively scarce existing literature has focused more on negative dependent measures like confrontation (e.g., LaFrance 1992). My experiments assessed status-related variables (e.g., dominance, influence and competence) and attraction-related variables (e.g., liking and disrespect), to determine if interruption can be utilized as a status-enhancing technique. Furthermore, previous research has left the question of whether interrupters are evaluated differentially as a function of gender unanswered. Some research has suggested that female interrupters are viewed less favorably than male interrupters (Chambliss and Feeny 1992; LaFrance 1992), but another study showed that interrupters are viewed similarly, regardless of gender (Robinson and Reis 1989). These experiments will add to the body of research experimentally investigating the effects of interruption.

Secondly, I examined the status implications for the targets of interruption. Research thus far has shown that targets of interruption suffer in terms of status, but only one of the three experimental studies utilized appropriate control groups (Robinson and Reis 1989). LaFrance (1992) compared interrupters to those they interrupted, so it is impossible to determine if effects were more status-enhancing for interrupters or more status-detracting for targets. Chambliss and Feeny (1992) focused only on cross-sex interruptions, so samesex conditions were not present for a baseline analysis. In order to improve upon existing research, both experimental and control groups were included, all possible dyads were compared, and observers completed status variables (dominance, influence, and competence) and attraction variables (liking and disrespect) on both persons in the dyad.

Finally, I explored the interpersonal reactions of being interrupted. Do targets of interruption interpret it the same way as observers do? Most importantly, does being interrupted interfere with perceptions of one's status? To my knowledge, Experiment 2 is the first experimental investigation of interruption in actual conversation. Because Experiment 2 involved the interruption of actual participants, I was able to determine if targets reacted to interruption by evaluating their own contributions to the dyad less favorably than those who were not interrupted.

Based on the literature presented, I predicted that interrupters would be perceived as having more status (dominance, competence and influence) than those who did not interrupt (Hypothesis 1), and that they would be liked less (and be viewed as more disrespectful) than those who did not interrupt (Hypothesis 2). I also hypothesized that due to status and expectancy effects, female interrupters would be viewed more negatively than male interrupters (Hypothesis 3) and that women interrupting men would be liked least (Hypothesis 4). Women, as lower status group members, should be evaluated harshly when they interrupt because interruption will not be perceived as legitimate. With regard to targets of interruption, I predicted that targets would lose status in comparison to those who were not interrupted (Hypothesis 5), especially men who were interrupted by women (Hypothesis 6). Finally, in Experiment 2, in which participants were the targets of interruption, I predicted that participants who were interrupted would assign themselves lower status ratings than participants who were not interrupted (Hypothesis 7).

\section{Experiment 1}

In this experiment, participants listened to a 5-min audiotaped interaction in which one person interrupted the other five times. Because the aim of the present experiments was to 
investigate the status-organizing effects of interruption, I combined aspects of deep and intrusive interruptions into my operational definitions (James and Clarke 1993; LaFrance 1992). In both experiments, interrupters initiated a change in topic in the main content of the other person's speech. So that interruptions would be perceived as truly intrusive and to preserve as much of the dialogue as possible (so content would not be confounded with condition), interruptions occurred at the end of the target's point (within the last 15 words). The first two interruptions, which involved overlapping speech for 6 and 7 words, respectively, were not successful. The last three interruptions were successful, but the target only left off 1-4 words of content. After listening to the audiotapes, participants evaluated both partners in the interaction on three status measures (competence, influence, and dominance) and two measures of likeability (liking and disrespect).

\section{Method}

\section{Participants}

A total of 109 students at Virginia Commonwealth University (85 women, 24 men) participated in return for partial course credit. Participants were ethnically diverse $(38.7 \%$ African-American, 35\% Caucasian-American, 9.9\% Asian American, 4.5\% Hispanic, and $9.9 \%$ who self-classified as mixed race or other). The average age of participants was 19 years. Participants were randomly assigned to one of eight conditions, and run in groups of two to eight.

\section{Audiotapes}

In this experiment, participants listened to an audiotape of two students discussing their opinions about an article printed in USA Today, which dealt with college entrance standards and remedial classes (Welsh 1999). Because the article was critical of the quality of the student body, I expected that it would be personally relevant to the students and that they would listen carefully to the audiotaped discussion.

Extensive pre-testing was conducted to create the script that was used in this experiment. Students from an upper-level psychology course $(N=20)$ read the article, indicated their opinion about it, and discussed arguments against the article in small groups of two to four people while being audiotaped. Next, a research assistant transcribed all non-redundant arguments (a total of 78) and 75 upper-level psychology students evaluated the arguments for argument strength.

I used the arguments to create a script of two people interacting. I created the script by selecting arguments of equal strength from each quartile and randomly assigning them to role so that both roles included weak and strong points. On a 7-point scale, the average strength rating of all arguments was 4.79 and both roles had an average strength rating of 4.81. I also controlled for the number of words spoken by each person (368 spoken by interrupter, 361 by target), and the recording time. For example, one of the arguments read, "Well, I think you should definitely require more of high schools" and another read "I always thought that the reasoning was, people who pay their tuition deserve to sit in on classes, but if they don't pass the class, then oh well, they don't deserve that piece of paper." The complete script is available upon request. In the interruption script, the target was interrupted during five out of ten spoken arguments, and these arguments were selected by chance. 
I created the audiotapes in a similar way as previous researchers (Chambliss and Feeny 1992; LaFrance 1992; Robinson and Reis 1989), because I believed that inserting interruptions through editing would diminish ecological validity. Four research assistants (two men and two women) practiced the two-person script multiple times with different partners, and then at least two tape recordings were made for each condition. As in LaFrance (1992), each research assistant was given a role (i.e., female interrupter, female target, male interrupter, male target) and played it for all conditions that required that role. The cleanest and most natural recording (without mistakes or extraneous noise) for each condition that most closely approximated five minutes in length was selected for each condition.

\section{Design and Procedure}

The experiment was a 2 (interrupter gender) $\times 2$ (condition: interruption, control) $\times 2$ (target gender) $\times 2$ (interactant rated) mixed-subjects experimental design. For ease of explanation, the first variable is called interrupter gender (even though this interactant only interrupted in the interruption condition). Similarly, the third variable is labeled target gender, even though this interactant is only a target in the interruption condition. The first three factors were between-subjects and interactant rated was within-subjects.

Participants read the USA Today article and indicated their attitude about it as a distracter task. Participants then listened to one of eight conversations and followed along with a transcript so that they knew who was speaking when. Next, participants completed items about both members of the dyad and a manipulation check on the following page ( "Did you happen to notice if one of the group members tended to interrupt the other? If yes, which member interrupted the other?"). Participants were then debriefed.

\section{Dependent Measures}

All dependent measures from Experiment 1 can be found in the Appendix. The first set of semantic differential items was obtained from LaFrance (1992). One group of items loaded heavily on the construct called "confrontation" by LaFrance (e.g., "argumentative/ agreeable"). This factor, called "dominance" in this research, could be categorized as a status measure (high status members are typically perceived as strong and assertive) or an attraction measure (clearly those who are overbearing are not well-liked). I categorized dominance as a status measure because the items seem highly linked to status expectations and would likely discriminate perceptions of high and low status individuals. The other factor, which relates to attraction/likeability, was labeled "disrespect" and included items such as "rude/polite." (LaFrance).

A set of 14 Likert-type items were adapted from Webster and Driskell's (1985) and Wood and Karten's (1986) research. The first two factors assessed relative status and were labeled competence and influence. The competence factor included five items and had a greater emphasis on trait ability (e.g., "_ was intelligent”), whereas the five-item influence factor measured situational influence (e.g., "- was an influential member of the group"). In contrast to previous studies on perception of interruption, a more direct measure of liking was also included. An example of the four-item factor was "_ has positive qualities." In sum, I included three status measures (dominance, competence, and influence) and two attraction/liking measures (liking and disrespect). 
Results

I subjected the factors to reliability analyses via Cronbach's alpha. So that results from Experiment 1 could be fairly compared to Experiment 2 (which utilized the same measures), I took into consideration the scale reliabilities from both experiments when making decisions about omitting items. I omitted items that, as a whole, detracted from the reliabilities in both studies (Omitted items are italicized in the Appendix). For example, when three items were removed from the influence subscale (i.e., Others encouraged _ to participate, I tended to agree with _ , and _ was not easily influenced by others), scale reliability improved .14 for targets in Experiment 1, .29 for interrupters in Experiment 1, .61 for confederates in Experiment 2, and .32 for participants in Experiment 2. Perhaps the nature of the manipulation rendered these items less meaningful than they would be in naturally occurring conversation. The final reliabilities for Experiment 1 were as follows: .68 for interrupter influence, .63 for target influence, .86 for interrupter dominance, .79 for target dominance, .71 for interrupter competence, .70 for target competence, .82 for interrupter disrespect, .71 for target disrespect, .75 for target likeability and .79 for interrupter likeability. Because the factors were adequately internally consistent, I combined items into five factors.

I computed correlations between measures on the sample of 111 participants. Influence and competence were positively correlated $(r=.65$ for interrupters, $r=.67$ for targets, $p<.01$ for both), but were less related to measures of likeability ( $r$ 's ranging from .00 to .43). Furthermore, disrespect and likeability were negatively related to one another $(r=-$ .72 for interrupters, $r=-.52$ for targets, $p<.01$ for both), but were distinct from influence and competence. The dominance measure was more related to the attraction measures than the status measures. For example, interrupter dominance was correlated at .74 with interrupter disrespect, and -.53 with interrupter likeability, but only .18 with interrupter competence and .31 with interrupter influence. However, because data analyses indicated that perceptions of interrupters and targets were similar for dominance, influence, and competence, the dominance measure was retained as a status measure.

In response to the manipulation check ("Did you happen to notice if one of the group members tended to interrupt the other?"), 88 out of 109 answered the question consistent with condition (81\%). Of those who were incorrect, 18 (16.5\%) misperceived the condition (noticing interruption when none occurred and failing to notice when it did occur). More participants erred on the side of perceiving interruption when none occurred. Perhaps this finding was due to demand characteristics of the question such that participants may have thought that because the question was asked, that interruptions did take place. In two other cases, participants misidentified the interrupter (instead listing the target). Because the vast majority of participants correctly identified condition, the manipulation was considered successful (no data were omitted from analyses).

All analyses were 2 (interrupter gender) $\times 2$ (condition: interruption, control) $\times 2$ (target gender) $\times 2$ (interactant rated, first versus second role) mixed-subjects Analyses of Variance (ANOVA's). Because the last variable, interactant rated, compares ratings for the first person on the tape to the second person on the tape, which includes both interrupting dyads and control dyads, the main effects will not be discussed here. For most variables (all except influence), the main effect for condition was significant, indicating that the pair was viewed more negatively in the interruption condition than in the control condition, but these effects were always qualified by higher-order interactions with the interactant variable. See Table 1 for all means associated with the main effects and interaction of interactant and condition. See Table 2 for descriptive statistics comparing all conditions on the dependent measures. 
Consistent with predictions, the interactant by condition interaction was significant for dominance, $F(1,103)=58.67, p<.001, \eta^{2}=.36$. Interrupters were viewed as more dominant than controls, $F(1,109)=58.12, p<.001, \eta^{2}=.35$, and targets as less dominant than respective controls, $F(1,109)=23.31, p<.001, \eta^{2}=.18$. The difference between roles was significant for the interruption condition, $F(1,54)=129.90, p<.001$, $\eta^{2}=.72$, but not the control condition, $F(1,49)=3.01, p>.05, \eta^{2}=.06$. Contrary to hypotheses, female interrupters were not viewed differently than male interrupters and no other significant effects were found.

The interactant by condition interaction was also significant for the competence variable, $F(1,103)=9.82, p=.002, \eta^{2}=.09$. Although competence ratings were not significantly different for interrupters and controls, $F(1,109)=.102, p=.75, \eta^{2}=.00$, targets of interruption were perceived as significantly less competent than controls, $F(1,109)=13.17, p=.002, \eta^{2}=.11$. The difference between roles was significant for the interruption condition, $F(1,55)=18.12, p<.001, \eta^{2}=.25$, but not the control condition, $F(1,54)=.29, p>.05, \eta^{2}=.01$. No other effects were observed for this variable.

There were similar effects for influence. The condition by interactant interaction was significant for influence, $F(1,103)=14.00, p<.001, \eta^{2}=.12$. Univariate analyses suggested that interrupters were perceived as significantly more influential than controls, $F(1,109)=4.22, p=.04, \eta^{2}=.04$, and targets of interruption were viewed as significantly less influential than controls, $F(1,109)=10.44, p=.002, \eta^{2}=.09$. As before, the difference between roles was significant for the interruption condition, $F(1,55)=19.88$, $p<.001, \eta^{2}=.26$, but not the control condition, $F(1,54)=.34, p>.05, \eta^{2}=.01$.

Furthermore, a three way interaction between interrupter gender, condition, and target gender was observed for influence, $F(1,103)=4.23, p=.042, \eta^{2}=.04$. For this interaction, the dyad was the unit of analysis. When the data were sorted by condition, influence ratings were marginally affected by gender in the interruption condition, $F(1,52)=3.15$, $p=.08, \eta^{2}=.06$, but not the control condition, $F(1,51)=1.33, p=.25, \eta^{2}=.03$. In the interruption condition, both members of the pair were viewed as "equally" influential ( $M$ influence of dyads ranging from 3.77 to 3.90), except for the woman interrupting the

Table 1 Main effect and interaction means for status and attraction variables in Experiment 1

\begin{tabular}{|c|c|c|c|c|c|c|}
\hline & \multicolumn{2}{|l|}{ Condition } & \multicolumn{4}{|c|}{ Interactant $\times$ Condition } \\
\hline & \multirow[b]{2}{*}{ Int. } & \multirow[b]{2}{*}{ Control } & \multicolumn{2}{|l|}{ Role 1} & \multicolumn{2}{|l|}{ Role 2} \\
\hline & & & Int. & Control & Target & Control \\
\hline \multicolumn{7}{|l|}{ Status } \\
\hline Dominance & $4.28(.55)$ & $4.04 *(.54)$ & $5.69(.95)$ & $4.21^{\mathrm{a}}(1.08)$ & $2.86(1.11)$ & $3.86^{\mathrm{a}}(.80)$ \\
\hline Competence & $3.55(.52)$ & $3.76^{*}(.49)$ & $3.76(.64)$ & $3.72(.67)$ & $3.33(.60)$ & $3.78^{\mathrm{a}}(.71)$ \\
\hline Influence & $3.73(.64)$ & $3.87(.61)$ & $4.13(.82)$ & $3.83^{\mathrm{a}}(.86)$ & $3.33(1.05)$ & $3.91^{\mathrm{a}}(.78)$ \\
\hline \multicolumn{7}{|l|}{ Attraction } \\
\hline Disrespect & $3.89(.64)$ & $3.39 *(.61)$ & 5.29 (1.09) & $3.86^{\mathrm{a}}(1.07)$ & $2.48(1.04)$ & $2.92^{\mathrm{a}}(.98)$ \\
\hline Likeability & $3.43(.53)$ & $3.71 *(.50)$ & $2.67(.86)$ & $3.47^{\mathrm{a}}(.81)$ & $4.19(.62)$ & $3.95(.72)$ \\
\hline
\end{tabular}

Note: * Groups differed significantly from one another $(p<.05)$

${ }^{\text {a }}$ Univariate means differed significantly from one another $(p<.05)$. Numbers in parentheses are standard deviations 
Table 2 Descriptive statistics for the dependent measures for interrupters, their targets, and their respective controls in Experiment 1

\begin{tabular}{|c|c|c|c|c|c|c|c|c|c|c|}
\hline \multirow[t]{2}{*}{ Condition } & \multicolumn{2}{|c|}{ Dominance } & \multicolumn{2}{|c|}{ Competence } & \multicolumn{2}{|c|}{ Influence } & \multicolumn{2}{|c|}{ Disrespect } & \multicolumn{2}{|c|}{ Likeability } \\
\hline & $M$ & $S D$ & $M$ & $S D$ & $M$ & $S D$ & $M$ & $S D$ & $M$ & $S D$ \\
\hline \multicolumn{11}{|l|}{$\mathrm{MIM}^{\mathrm{a}}$} \\
\hline Male interrupter & 5.35 & 1.14 & 3.89 & .43 & 4.08 & .76 & 5.02 & 1.07 & 2.87 & .97 \\
\hline Male target & 3.16 & 1.21 & 3.46 & .44 & 3.65 & .83 & 2.60 & 1.17 & 4.26 & .68 \\
\hline \multicolumn{11}{|l|}{$\mathrm{MCM}^{\mathrm{b}}$} \\
\hline Male control & 4.54 & .76 & 3.76 & .59 & 3.61 & .92 & 4.31 & 96 & 3.36 & .81 \\
\hline Male partner & 3.76 & .73 & 3.96 & .78 & 3.93 & .76 & 3.05 & 1.03 & 4.24 & .63 \\
\hline \multicolumn{11}{|l|}{$\mathrm{MIF}^{\mathrm{a}}$} \\
\hline Male interrupter & 5.85 & .75 & 3.65 & .48 & 3.81 & 1.01 & 5.38 & .88 & 2.49 & .73 \\
\hline Female target & 2.42 & 1.11 & 3.25 & .33 & 3.00 & 1.08 & 2.38 & .86 & 4.31 & .42 \\
\hline \multicolumn{11}{|l|}{$\mathrm{MCF}^{\mathrm{b}}$} \\
\hline Male control & 4.04 & .86 & 3.48 & .59 & 3.89 & .74 & 3.77 & 1.20 & 3.60 & .83 \\
\hline Female partner & 3.38 & .73 & 3.71 & .79 & 4.00 & .94 & 2.43 & .87 & 4.07 & .80 \\
\hline \multicolumn{11}{|l|}{ FIM $^{\mathrm{a}}$} \\
\hline Female interrupter & 5.89 & .96 & 3.78 & .79 & 4.27 & .60 & 5.73 & .97 & 2.79 & .91 \\
\hline Male target & 2.80 & 1.00 & 3.26 & .42 & 3.27 & .97 & 2.15 & .93 & 4.10 & .71 \\
\hline \multicolumn{11}{|l|}{$\mathrm{FCM}^{\mathrm{a}}$} \\
\hline Female control & 4.24 & .97 & 3.95 & .76 & 4.08 & .95 & 3.83 & .62 & 3.36 & .64 \\
\hline Male partner & 4.11 & .76 & 3.86 & .59 & 3.92 & .70 & 2.94 & .89 & 3.94 & .72 \\
\hline \multicolumn{11}{|l|}{$\mathrm{FIF}^{\mathrm{c}}$} \\
\hline Female interrupter & 5.55 & 1.02 & 3.73 & .79 & 4.38 & .70 & 5.07 & 1.31 & 2.55 & 1.01 \\
\hline Female target & 3.19 & 1.08 & 3.34 & .93 & 3.41 & 1.24 & 2.79 & 1.14 & 4.10 & .66 \\
\hline \multicolumn{11}{|l|}{$\mathrm{FCF}^{\mathrm{b}}$} \\
\hline Female control & 3.91 & 1.46 & 3.71 & .70 & 3.75 & .91 & 3.54 & 1.30 & 3.57 & .66 \\
\hline Female partner & 4.05 & .99 & 3.61 & .70 & 3.79 & .78 & 3.27 & 1.00 & 3.55 & .58 \\
\hline
\end{tabular}

Note: For condition, $\mathrm{M}=$ male, $\mathrm{F}=$ female, $\mathrm{I}=$ interruption, and $\mathrm{C}=$ control

${ }^{\mathrm{a}} n=13,{ }^{\mathrm{b}} n=14,{ }^{\mathrm{c}} n=17$

man condition in which both members dropped significantly in influence, $M=3.4$. No other significant effects were observed.

A significant interaction between interactant and condition was also found for disrespect, $F(1,103)=36.42, p<.001, \eta^{2}=.26$. Consistent with hypotheses, individuals who interrupted were seen as significantly more disrespectful than controls, $F(1,109)=48.11$, $p<.001, \eta^{2}=.31$, and targets were viewed as significantly less disrespectful than controls, $F(1,109)=4.72, p=.03, \eta^{2}=.04$. Although the difference between roles was significant for both conditions, this difference was much stronger for the interruption condition, $F(1,55)=133.5, p<.001, \eta^{2}=.71$, than the control condition, $F(1,54)=$ 21.36, $p<.001 . \eta^{2}=.28$.

A significant three-way interaction between interactant, interrupter gender, and target gender was found for disrespect, $F(1,103)=4.28, p=.04, \eta^{2}=.04$. The interaction between interrupter gender and target gender was not significant for interrupters, because all interrupters were viewed as highly disrespectful, $F(1,107)=.35, p=.55, \eta^{2}=.00$, but was significant for targets, $F(1,107)=5.32, p=.02, \eta^{2}=.05$. Participants gave 
higher disrespect ratings to targets in same-gender dyads $(M=2.83$ for male dyad and $M=3.03$ for female dyad) than targets in mixed-gender dyads $(M=2.41$ for $\mathrm{M}-\mathrm{F}$ and $M=2.55$ for F-M dyad). No other significant effects were found.

The predicted interactant by condition interaction was also significant for the liking measure, $F(1,103)=25.36, p<.001, \eta^{2}=.20$. There was no significant difference in liking between targets and controls, $F(1,109)=3.44, p=.07, \eta^{2}=.03$, but interrupters were liked much less than controls, $F(1,109)=26.42, p<.001, \eta^{2}=.20$. As with disrespect, the difference between roles was significant for both conditions, but this difference was much stronger for the interruption condition, $F(1,55)=100.76, p<.001, \eta^{2}=.65$, than the control condition, $F(1,54)=11.59, p=.001, \eta^{2}=.18$.

A significant interactant by condition by interrupter gender was found for liking, $F(1,103)=4.17, p=.04, \eta^{2}=.04$. For this interaction, the greatest disparity in liking between members of the pair occurred when the woman interrupted. The female interrupter was liked much less $(M=2.52)$ than her targets were $(M=4.20)$, regardless of target gender, but no other significant effects were found.

\section{Discussion}

In support of Hypothesis 1, the second interactant role was perceived to be more dominant and influential (but not more competent) in the interruption condition than in the control condition. As Hypothesis 2 predicted, this increase in status came at the expense of likeability as interrupters were liked significantly less and viewed as more disrespectful than those who did not interrupt. Furthermore, consistent with Hypothesis 5, targets of interruption were viewed as less dominant, less influential, and less competent than those who were not interrupted. These findings are consistent with previous experiments in this area (Chambliss and Feeny 1992; LaFrance 1992; Robinson and Reis 1989). Because this experiment compared interrupters and targets to their respective controls in addition to one another, it was possible to demonstrate that both interrupters and their targets were perceived differently following interruption.

This research offered some limited support for the gender predictions. Overall, female interrupters received similar status ratings to male interrupters. But interestingly, when the dyad was the unit of analysis, the woman interrupting the man condition had the lowest influence ratings of any dyad, so men were only negatively evaluated when interacting with female interrupters, in keeping with Hypothesis 6. Gender also affected liking ratings. Results clearly supported Hypothesis 3. As in LaFrance (1992), female interrupters were liked significantly less than their targets, regardless of who their targets were. While female interrupters were not especially disliked when interrupting men (Hypothesis 4), this finding may be interpreted in light of a backlash against female interruption. Consistent with legitimacy processes, the illegitimate attempt of low status members to engage in high status behavior was costly to their liking ratings (Ridgeway 1982).

It is important to address one limitation of Experiment 1. To increase the ecological validity of the manipulation, I chose not to insert interruptions through editing. Rather, I attempted to select the most natural sounding tape per condition which most closely approximated five minutes in length. Despite the controls, it is possible that confederates spoke more loudly or assertively in the interruption conditions as compared to the control conditions (Lewis et al. 1997). Nonetheless, it is likely that speech volume and assertiveness naturally covary with intrusive interruptions in everyday conversation, as those who engage in intrusive interruption are, by definition, attempting to prevent the other person from speaking. 
Despite this limitation, this experiment adds to the body of research which implicates interruption as a status-organizing behavior. This experiment extends previous research in that (a) interruption was shown to affect more evaluatively positive dependent measures (i.e., influence), and (b) interrupters and their targets were found to differ significantly from respective controls. Of critical importance was the finding that targets of interruption were viewed as having less status than controls, simply due to being interrupted. It would be interesting to determine if a similar pattern of results emerges with different types of interruption (interrupting to agree, etc.).

\section{Experiment 2}

Experiment 2 involved interruption in actual conversation, so it provided a framework for examining how expectations relate to how interruptions are perceived by the target. More importantly, the experiment was able to reveal whether or not interruption negatively influences self-perceptions. In Experiment 2, trained female and male confederates interrupted participants during conversation. After the experimental sessions, participants evaluated confederates on measures of status and likeability, and rated their own ability in the conversation.

\section{Method}

\section{Participants}

A total of 187 students at Virginia Commonwealth University obtained partial course credit for participation. Of the 187 participants, 27 were omitted for the following reasons: 23 due to suspicion, 1 due to participating twice, 2 due to the brevity of the interaction, and 1 due to being informed about the study's purpose before participating. Therefore, based upon participants' responses to the "suspicion" items, 88\% (164 of 187) reported no awareness of the use of a confederate to manipulate interruption.

Of the "suspicious" participants, 15 were in the interruption condition (8 male participants and 7 female participants), and 8 in the control condition (5 men and 3 women). These omissions were taken into account during data collection, so data analyses were conducted on 160 participants ( 80 men and 80 women).

Each participant was matched with a confederate and randomly assigned to condition, creating a total of 160 participant-confederate dyads. Only participants who self-identified as white were eligible for this study to minimize the possibility that more than one status characteristic was activated. However, because of inconsistencies in how participants selfidentified (from the questionnaire at the beginning of the semester to the post-experimental questionnaire in the study), one Native American and three mixed-race participants were also included. The average age of participants was 19 .

\section{Materials}

As in the first experiment, the topic of discussion was the article printed in USA Today. The materials used in this experiment also included the article, the Attitude Toward the Article questionnaire, and the dependent variable questionnaire. All dependent items from Experiment 1 were used in Experiment 2 to rate the confederate (11 semantic differential items and 14 Likert-type items). In addition, participants completed self-ratings on 
competence and influence (See Appendix for items). For example, participants rated both themselves and the confederates on intelligence and general capability. On the final page of the questionnaire, two questions were included to determine if participants' suspicion was aroused ("What did you think this study was about?" and "Did you notice anything unusual about this study?").

I derived the confederate script from the first role in Experiment 1. The script consisted of 10 short arguments, none of which were related. The only changes made to the script were in the introductions. Confederates introduced themselves using their real names, and said, "This is the first time I have heard about this article. What did you think about it?"

\section{Confederate Training and Pilot Testing}

Four trained confederates (two women and two men) learned the script word for word before practicing the script with each other. The confederates were trained to act as similarly as possible. In each session, confederates allowed participants to introduce themselves first, then introduced themselves and prompted participants to discuss their thoughts. For non-interrupted arguments, confederates waited until participants had completely finished their thoughts before starting their scripted arguments. In this way, conversational control was alternated. If asked a question, confederates answered the question briefly if it pertained to something they had said (typically repeating elements of the scripted argument), or said "I don't know" in all other situations (for example, if the participant asked, "What do you think the author meant by _?").

Confederates' nonverbal behavior was carefully controlled. They were instructed to avoid nodding, smiling, back-channel utterances (brief affirmative responses such as "uhhuh"), and excessive gesturing. Confederates maintained natural, attentive eye contact, and glanced down at the article if it became uncomfortable. Most importantly, it was emphasized to confederates that they act as similarly as possible in the control and experimental conditions.

As in Experiment 1, interruptions in this experiment were deep (involving a topic change) and intrusive because these types are linked with higher status (Anderson and Leaper 1998). Specifically, confederates interrupted 2-s (or about 15 words, whichever came first) into the participant's utterance. I operationally defined interruption in this way so that confederates would likely be interrupting the real content of the participants' comment. In situations in which participants were reluctant to give up the floor, confederates were trained to repeat the first couple of words over and over again until the participants stopped talking. That is, successful interruptions were attempted, but because a number of participants did not yield the floor, interruptions were not always successful.

After confederate training, pilot testing began. A total of 20 pilot participants were run through the protocol. For pilot testing, confederates only practiced the interruption condition, and were trained to interrupt their targets five times during the group discussion. After pilot testing, two major changes were made to the protocol. First, in response to the verbal manipulation check ("Did you happen to notice if your partner interrupted you during your conversation?"), $50 \%$ of the pilot participants did not notice the interruptions. Both theoretical formulations require that the manipulation be salient in order to test theoretical predictions. Wagner (1988) argued that in order for deviance to be perceived, the status-expectation violation needs to be persistent, and Burgoon and Hale (1988), wrote that "experimental tests (of EVT) must necessarily operate within the range of moderate to large violations if statistically significant results are to be obtained" (p. 77). Consequently, I increased the manipulation to eight interruptions out of 10 arguments for the remainder of 
the participants (only the first and fifth arguments were not interrupted). One other issue was that some of the participants reacted to the interruptions with silence, refusing to speak after being interrupted. Because the deception would become more obvious if confederates interrupted targets after a long period of silence, sessions were terminated after about $10 \mathrm{~s}$ of silence or after the confederate completed all ten arguments.

\section{Design and Procedure}

The design of Experiment 2 was a 2 (participant gender) $\times 2$ (condition: interruption versus control) $\times 2$ (confederate gender) $\times 2$ (person rated) mixed-subjects factorial design. The design was completely between-subjects for three factors (dominance, liking, and disrespect), but confederates completed measures on the confederates and themselves for influence and competence.

Two female experimenters ran all of the sessions for the present study. The experimenter seated the participant and the confederate in different rooms while the participant read the article and indicated his/her opinion about it. After random assignment, the confederate was brought into the room with the participant. The experimenter instructed the dyad to discuss arguments against the article.

The participant introduced him/herself first, followed by the confederate, who asked the participant what s/he thought about the article. In the control condition, confederates waited until the participants had finished their comments, then made one scripted argument, and waited for the participant to speak again. Consequently, control of the floor was alternated. In the interruption condition, confederates interrupted eight out of 10 of the participants' comments (all but the first and fifth). After the confederate made all ten scripted arguments, or after approximately ten seconds of silence, sessions were terminated and the confederate returned to his/her original room so participants could complete dependent measures. Participants were then given a verbal manipulation check (Did you happen to notice if your partner interrupted you during your conversation?). Then, participants were debriefed.

Results

When asked, "Did you happen to notice if your partner interrupted you during your conversation?" 141 of 160 (88\%) were correct about their condition. Of those who were not correct, 10 were incorrect (failed to notice when interruption occurred or perceived interruption when none occurred), and 9 were not sure. The manipulation check was considered successful due to the large percentage correct on this measure.

I conducted reliability analyses on the dependent variables for Experiment 2 in the same way that I did for Experiment 1. I attempted to create similar subscales (dominance, competence, influence, disrespect, and likeability) for the dependent measures so that results could be compared across studies. The items on the subscales were identical except for the addition of one item on the likeability measure. The alphas, which were based on an $N$ of 160 , were as follows: dominance ( $\alpha=.81$ for confederate), competence $(\alpha=.72$ for both confederate and self), influence ( $\alpha=.63$ for confederate and .66 for self), and disrespect $(\alpha=.78$ for confederate). Likeability was more internally consistent when the selection item (I would select $\mathrm{X}$ as a group member if I were working on a similar task) was included $(\alpha=.85)$. Because participants in Experiment 2 actually interacted with confederates, this item seemed more relevant to this experiment than Experiment 1. Because the factors were adequately internally consistent, items were combined into five measures. 
The pattern of intercorrelations between measures was similar for Experiment 2 as it was for Experiment 1. Influence and competence were positively correlated $(r=.59$ for interrupters, $r=.67$ for targets, $p<.01$ for both), but were less related to measures of likeability (absolute value of $r$ 's ranging from .17 to .49). Furthermore, disrespect and likeability were negatively related to one another $(r=-.71, p<.01)$, but were less related to influence and competence (the highest was between interrupter competence and interrupter likeability, $r=.49$ ). As in Experiment 1 , the dominance measure was more related to the attraction measures than the status measures. For example, interrupter dominance was correlated at .66 with interrupter disrespect, and -.48 with interrupter likeability, but only .04 with interrupter competence and .23 with interrupter influence. However, because data analyses indicated that perceptions of interrupters and targets were similar for dominance, influence, and competence, the dominance measure was retained as a status measure.

All analyses were 2 (participant gender) $\times 2$ (condition: interruption versus control) $\times 2$ (confederate gender) $\times 2$ (person rated) factorial Analyses of Variance (ANOVA's). The dominance, disrespect, and likeability measures were obtained only for confederates, so a completely between-subjects ANOVA was used for these tests. The influence and competence measures were obtained for both the confederate and the participant, so interactant was added as a within-subjects factor for these two variables. See Table 3 for descriptive statistics for all conditions.

Confederates were rated higher on dominance in the interruption condition $(M=4.75)$ than in the control condition $(M=3.59), F(1,152)=56.95, p<.001, \eta^{2}=.27$. A condition by participant gender interaction was also significant, $F(1,152)=4.99, p=.03$, $\eta^{2}=.03$. Specifically, in the control conditions, male and female participants rated confederates similarly, $F(1,78)=.00, p=.96, \eta^{2}=.00$, but female participants viewed interrupters as more dominant $(M=5.09)$ than male participants did $(M=4.44)$, $F(1,78)=8.31, p=.005, \eta^{2}=.10$. Female participants also perceived the confederates as more dominant $(M=4.34)$ than male participants did $(M=4.01)$, regardless of

Table 3 Descriptive statistics for all dependent measures in Experiment 2

\begin{tabular}{|c|c|c|c|c|c|c|c|c|c|c|c|c|c|c|}
\hline \multirow[t]{3}{*}{ Condition } & \multicolumn{10}{|c|}{ Confederate measures } & \multicolumn{4}{|c|}{ Participant self-ratings } \\
\hline & \multicolumn{2}{|c|}{ Dominance } & \multicolumn{2}{|c|}{ Competence } & \multicolumn{2}{|c|}{ Influence } & \multicolumn{2}{|c|}{ Disrespect } & \multicolumn{2}{|c|}{ Likeability } & \multicolumn{2}{|c|}{ Competence } & \multicolumn{2}{|c|}{ Influence } \\
\hline & $M$ & $S D$ & $M$ & $S D$ & $M$ & $S D$ & $M$ & $S D$ & $M$ & $S D$ & $M$ & $S D$ & $M$ & $S D$ \\
\hline $\mathrm{MIM}^{\mathrm{b}}$ & 4.32 & 1.36 & 3.90 & .54 & 4.35 & .59 & 3.64 & .92 & 3.56 & .72 & 4.07 & .43 & 3.98 & .87 \\
\hline $\mathrm{MIF}^{\mathrm{b}}$ & 5.14 & .71 & 4.05 & .47 & 4.45 & .48 & 4.08 & .99 & 3.38 & .89 & 3.82 & .51 & 3.58 & .83 \\
\hline FIM $^{\mathrm{a}}$ & 4.51 & .83 & 3.89 & .88 & 4.00 & .87 & 3.65 & 1.16 & 3.66 & .90 & 3.76 & .58 & 3.63 & .66 \\
\hline $\mathrm{FIF}^{\mathrm{c}}$ & 5.04 & 1.17 & 4.15 & .60 & 4.33 & .53 & 3.75 & 1.47 & 3.29 & 1.16 & 3.96 & .48 & 3.67 & .75 \\
\hline $\mathrm{MCM}^{\mathrm{a}}$ & 3.74 & .88 & 3.78 & .42 & 3.84 & .91 & 3.34 & .94 & 3.70 & .66 & 3.80 & .62 & 3.71 & .78 \\
\hline $\mathrm{MCF}^{\mathrm{b}}$ & 3.40 & .78 & 3.99 & .54 & 3.88 & .92 & 2.61 & 1.03 & 3.91 & .78 & 4.05 & .49 & 4.18 & .59 \\
\hline $\mathrm{FCM}^{\mathrm{c}}$ & 3.46 & .66 & 3.89 & .53 & 4.12 & .63 & 2.61 & .76 & 4.07 & .69 & 3.89 & .47 & 4.07 & .55 \\
\hline $\mathrm{FCF}^{\mathrm{b}}$ & 3.76 & 1.16 & 4.06 & .76 & 4.05 & 1.02 & 3.04 & 1.21 & 3.83 & .90 & 4.02 & .64 & 4.03 & .85 \\
\hline
\end{tabular}

Note: For condition, $\mathrm{M}=$ male, $\mathrm{F}=$ female, $\mathrm{I}=$ interruption, and $\mathrm{C}=$ control. $\mathrm{In}$ addition, the first person listed is the confederate. For example, in the first condition, a male confederate interrupted a male participant

${ }^{\mathrm{a}} n=19,{ }^{\mathrm{b}} n=20,{ }^{\mathrm{c}} n=21$ 
condition, $F(1,152)=4.51, p=.04, \eta^{2}=.03$. No other significant gender effects were found.

The interactant by condition interaction was significant for influence, $F(1,152)=$ 14.18, $p<.001, \eta^{2}=.09$. Participants rated confederates as more influential in the interruption conditions $(M=4.29)$ than in the control conditions $(M=3.98), F(1,158)=$ $6.68, p=.01, \eta^{2}=.04$, and rated themselves as less influential in the interruption conditions $(M=3.71)$ than in the control conditions $(M=4.00), F(1,158)=5.91, p=.02$, $\eta^{2}=.04$. Regardless of condition, participants assigned confederates higher influence ratings $(M=4.13)$ than themselves $(M=3.85), F(1,152)=11.99, p=.001, \eta^{2}=.07 . \mathrm{I}$ found no significant gender effects for influence. There were no significant effects for the competence factor.

The main effect for condition was significant for disrespect, $F(1,152)=26.45$, $p<.001, \eta^{2}=.15$, and for likeability, $F(1,152)=9.05, p=.003, \eta^{2}=.06$. Participants found interrupters to be significantly more disrespectful $(M=3.78)$ and less likable $(M=3.47)$ than controls. In addition, there was a significant three-way interaction between participant gender, condition, and confederate gender for disrespect, $F(1,152)=$ $4.82, p=.03, \eta^{2}=.03$. However, contrary to hypotheses, the condition by participant gender interaction was significant for male interrupters, $F(1,75)=7.12, p=.009$, $\eta^{2}=.09$, but not for female interrupters, $F(1,77)=.41, p=.53, \eta^{2}=.01$. Women who were interrupted viewed male confederates as much more disrespectful $(M=4.08)$ than men who were interrupted $(M=3.64)$, but women who were not interrupted rated male confederates as much less disrespectful $(M=2.61)$ than men who were not interrupted $(M=3.34)$.

The hypothesized gender predictions were not supported in Experiment 2. Specifically, female interrupters were not viewed differently than male interrupters with regard to the status or attraction measures. There was an overall trend for female interrupters to gain in status similarly to male interrupters, and to be disliked similarly to male interrupters.

\section{General Discussion}

As predicted, interruption is a behavior that influences perceptions of status. In Experiment 1 , interruption is interpreted as a status cue such that observers rated interrupters as more dominant and influential than controls. The effect of interruption on targets was perhaps more interesting - targets of interruption were viewed as significantly less dominant, competent, and influential than their respective controls. Merely having been interrupted reduced the ratings observers assigned to targets' influence, intelligence, etc. Experiment 2 yielded similar effects, with interrupters gaining status and targets losing it. Specifically, in the interruption condition, confederates were viewed as significantly more dominant and influential than controls (supporting Hypothesis 1), and targets of interruption viewed interrupters as significantly more influential than themselves (supporting Hypothesis 7). If one wants to appear competent, influential, dominant and assertive, it appears that interruption is an effective means for impression-management. However, this tactic clearly has its associated costs. Consistent with Hypothesis 2, interrupters were disliked in both experiments and interestingly, targets of interruption were liked more than their respective controls. Therefore, asserting oneself through interruption may make one appear more influential, but can negatively affect interpersonal relations.

In keeping with theoretical predictions (Skvoretz and Fararo 1996), the research presented here indicated that behavior organizes status. Regardless of what they say, talkative 
people are assumed to be leaders (Malloy and Janowski 1992; Schmid Mast 2002). Because powerful people tend to behave in powerful ways, people ascribe status to those engaging in powerful behavior, regardless of the legitimacy of the behavior. Individuals who interrupted others were assigned greater status than individuals who did not interrupt, even though the content of the arguments was exactly the same. It is worth mentioning that interruptions in these studies merely prevented targets from speaking; Interrupters did not disagree with target's arguments. Simply preventing another person from speaking makes one seem influential. This finding adds additional weight to the importance of paralinguistic cues.

Of importance was the finding that interruption caused targets to rate themselves lower on the influence variable in Experiment 2. Not only was it the case that observers viewed targets as less dominant, competent and influential than controls, but targets of interruption rated themselves as less influential in the interruption condition than in the control condition. One could argue that because interruptions prevented participants from speaking in Experiment 2, that indeed, participants were less influential in the interruption condition than the control condition. However, targets also lost status in Experiment 1. In Experiment 1 , participants heard exactly the same content in the interruption and control conditions with the exception of 8 words, and still interpreted targets as less influential. This evidence bolsters support for the idea that the presence of interruptions itself is responsible for altering perceptions of the interactants. Targets interpreted interruption as an expressive task cue (a behavior that communicates status-relevant information) (Ridgeway et al. 1985; Ridgeway and Berger 1986), and responded by decreasing their status self-ratings.

There was limited support for gender predictions in these experiments. Hypotheses 3 predicted that female interrupters would be evaluated more harshly than male interrupters, especially when interrupting men (Hypothesis 4). I also expected that men who were interrupted by women would experience the lowest status ratings (Hypothesis 6). In Experiment 1, the female interrupting the male pair received the lowest influence ratings, offering some support for Hypotheses 3 and 6. Men lost status when women interrupted them. Additional support for Hypothesis 3 was found in the liking ratings-women were liked much less than their targets, regardless of who their targets were. Coupled together, these effects offer some support for the gender hypotheses, but there were no significant gender interactions in Experiment 2. The relationship between gender, interruption, and status has been inconsistent in previous work. While some research has found female interrupters to be more assertive than male interrupters (Chambliss and Feeny 1992; Wiley and Woolley 1988), other research has indicated that men and women who interrupt are viewed similarly (Robinson and Reis 1989).

One explanation for the lack of significant gender effects in Experiment 2 is consistent with the assumptions of Expectation States Theory (EST). Participants in this experiment rated confederates as more competent than themselves, regardless of condition. It is possible that because confederates possessed a wider range of arguments, they were perceived as more knowledgeable, and this knowledge functioned as a specific status characteristic. In situations in which a specific status characteristic is present, such as perceived expertise, the characteristic is combined in an additive fashion with salient diffuse status characteristics (Ridgeway 1982). Consequently, participants ascribed the confederates more status, regardless of gender and gender effects were less prominent.

In addition, recent research has cast doubt on the automatic activation of gender as a diffuse status characteristic (Foschi and Lapointe 2002; Rashotte and Webster 2005). While some studies continue to find gender effects consistent with predictions of EST (Hopcroft 2002), others have not. Because women are achieving greater power in society, 
perhaps gender is not always regarded as a reliable status cue. In several of the studies Foschi and Lapointe reviewed, there were weak, if not nonexistent, gender effects.

The hypotheses for these experiments were also derived from theoretical predictions of Expectancy Violations Theory (EVT). One significant aspect of EVT's theoretical framework concerns the ambiguity of nonverbal behaviors (NVBs). Many NVBs are polysemous, that is, they have multiple meanings, but these meanings are constrained by aspects of the situation (Burgoon 1993; Burgoon and Hale 1988). EVT argues that aspects of the communicator (like gender) are more important when a violation's meaning is unclear. In cases in which the violation has a clear meaning (as in the case of intrusive interruption in these experiments), the violation will have similar consequences for high and low reward communicators (Burgoon 1993). In these experiments, there was little room for participants to ascribe a more positive meaning for these interruptions as a function of interrupter sex (because the intent was clearly negative), and so gender became less relevant (Burgoon and Hale 1988).

My attempt to control argument strength and words spoken for the two roles was successful in that analyses showed no difference between the roles in the control conditions for the three status variables. It was the case that the second role was perceived as less likable and more disrespectful than the first role in both conditions, but the effect sizes show that the difference between roles was significantly greater in the interruption conditions than the control conditions. Perhaps comments by the second role were interpreted as more arrogant than those of the first. As a consequence, the interrupter versus target difference in the experimental condition should be appraised relative to the same comparison in the control condition.

One limitation to the present experiments relates to the use of an experimental design. A number of variables that were carefully controlled, such as the use of a script, the timing of the interruptions, the minimization of other nonverbal behaviors, reduced external validity. For example, out of necessity, participants in Experiment 2 were exposed to non-smiling confederates who adhered to a script, regardless of the content of their points. In addition, because this was the first experimental manipulation of interruption in conversation, it was necessary to implement a rather strong manipulation to determine if interruption did indeed influence perceptions (Burgoon and Hale 1988; Wagner 1988). It could be argued the high rate of interruption experienced by my participants is unusual. However, contrary to my expectations and the expectations of my confederates, many participants did not notice the manipulation in Experiment 2, which is consistent with the NVB's influencing us on a "tacit and unconscious" level (Hall et al. 2005, p. 899).

It would be important for organizations to recognize that individuals who talk a great deal, interrupt others, and maintain high levels of eye contact while speaking are believed to possess higher status, regardless of the content of communications (Hall et al. 2005; Malloy and Janowski 1992). Furthermore, individuals who allow others to interrupt them pay a large price for failing to be assertive.

The experimental investigation of interruption in conversation is a ripe area of study. One idea involves manipulating status position, performance quality, and the presence or absence of interruption. Leaders who have acquired legitimacy would be expected to interrupt, and as such, would be better liked when they engage in this behavior than when they do not. In contrast, leaders with poor leadership quality would be disliked more when they interrupt because their leadership would be perceived as illegitimate. This would be a good way to disentangle gender from formalized status, since gender does not always operate as a status cue. 
With regard to Experiment 2, it would be interesting to learn the extent to which other nonverbal behaviors coincide with the "lower status" ascribed to targets of interruption. Do targets of interruption behave more submissively than non-targets in terms of their nonverbal behaviors (e.g., smiling, touching)? Another direction of future research involves manipulation of status through false feedback on a specific status characteristic, gender of participant, and condition (interruption versus control). This experiment would more accurately gauge the relative influence of specific status characteristics or gender on perceptions of interruptive behavior. It would also be interesting to manipulate other higher-status expressive task cues like gaze duration, time spent talking and posture to determine their status and liking implications.

\section{Appendix}

Dependent Measures from Both Experiments

Please read the following scales carefully, and use them to describe your opinion about the first person on the tape.

\begin{tabular}{llllllllll}
\hline Rude & 1 & 2 & 3 & 4 & 5 & 6 & 7 & Polite $^{\mathrm{d}}$ & $\mathrm{r}$ \\
Agreeable & 1 & 2 & 3 & 4 & 5 & 6 & 7 & Argumentative $^{\mathrm{b}}$ & \\
Passive & 1 & 2 & 3 & 4 & 5 & 6 & 7 & Assertive $^{\mathrm{b}}$ & \\
Caring & 1 & 2 & 3 & 4 & 5 & 6 & 7 & Indifferent $^{\mathrm{d}}$ & \\
Irrational & 1 & 2 & 3 & 4 & 5 & 6 & 7 & Rational $^{\mathrm{b}}$ & \\
Strong & 1 & 2 & 3 & 4 & 5 & 6 & 7 & Weak $^{\mathrm{b}}$ & $\mathrm{r}$ \\
Pleasant & 1 & 2 & 3 & 4 & 5 & 6 & 7 & Irritable $^{\mathrm{d}}$ & \\
Submissive & 1 & 2 & 3 & 4 & 5 & 6 & 7 & Dominant $^{\mathrm{b}}$ & \\
Cooperative & 1 & 2 & 3 & 4 & 5 & 6 & 7 & Competitive $^{\mathrm{b}}$ & \\
Overbearing & 1 & 2 & 3 & 4 & 5 & 6 & 7 & Understanding $^{\mathrm{b}}$ & $\mathrm{r}$ \\
Concerned & 1 & 2 & 3 & 4 & 5 & 6 & 7 & Concerned $^{\mathrm{d}}$ & \\
With other & & & & & & & & With self & \\
\hline
\end{tabular}

Now please read the following statements carefully and indicate the extent to which you agree with them using the following numbers:

$1=$ Strongly Disagree

2 = Mildly Disagree

$3=$ Neither Agree nor Disagree

$4=$ Mildly Agree

$5=$ Strongly Agree

_1. Jane would perform well at tasks in general. ${ }^{\mathrm{a}}$

2. Jane was an influential member of this group. ${ }^{c}$

3. Jane was a likable member of this group. ${ }^{\mathrm{e}}$

-4. Jane was intelligent. ${ }^{\mathrm{a}}$

5. Other group members encouraged Jane to participate. ${ }^{\mathrm{c}}$

-6. I tended to agree with Jane. ${ }^{\mathrm{c}}$

7. Jane made strong arguments. ${ }^{\mathrm{a}}$ 
Appendix continued

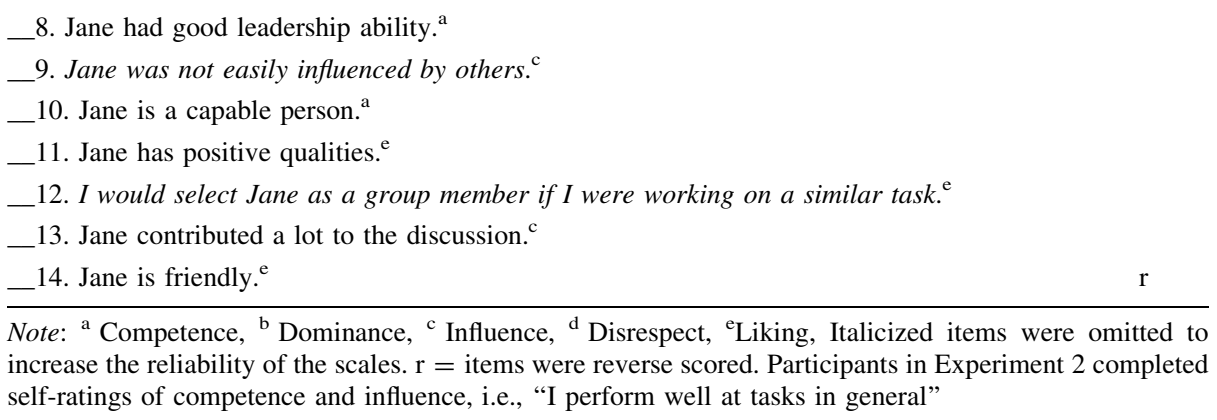

\section{References}

Anderson, K. J., \& Leaper, C. (1998). Meta-analyses of gender effects on conversational interruption: Who, what, when, where, and how. Sex Roles, 39(3/4), 225-252.

Aries, E. (1998). Gender differences in interaction: A reexamination. In D. J. Canary \& K. Dindia (Eds.), Sex differences and similarities in communication: Critical essays and empirical investigations of sex and gender in interaction (pp. 65-81). Mahwah, NJ: Lawrence Erlbaum Associates.

Beattie, G. W. (1981). Interruption in conversational interaction, and its relation to the sex and status of the interactants. Linguistics, 19, 15-35.

Berger, J. (1974). Expectation states theory: A theoretical research program. In J. Berger, T. L. Conner, \& M. H. Fisek (Eds.), Expectation states theory: A theoretical research program (pp. 3-22). Cambridge, MA: Winthrop Publishers, Inc.

Berger, J., Cohen, B. P., \& Zelditch, M, Jr. (1972). Status characteristics and social interaction. American Sociological Review, 37, 241-255.

Burgoon, J. K. (1993). Interpersonal expectations, expectancy violations, and emotional communication. Journal of Language and Social Psychology, 12, 30-48.

Burgoon, J. K., \& Dunbar, N. E. (2006). Nonverbal expressions of dominance and power in human relationships. In V. Manusov \& M. L. Patterson (Eds.), The Sage handbook of nonverbal communication (pp. 279-297). Thousand Oaks, CA: Sage.

Burgoon, J. K., \& Ebesu Hubbard, A. S. (2005). Cross-cultural and intercultural applications of expectancy violations theory and interaction adaptation theory. In W. Gudykunst (Ed.), Theorizing about intercultural communication (pp. 149-171). Thousand Oaks, CA: Sage.

Burgoon, J. K., \& Hale, J. L. (1988). Nonverbal expectancy violations: Model elaboration and application to immediacy behaviors. Communication Monographs, 55, 58-79.

Chambliss, C. A., \& Feeny, N. (1992). Effects of sex of subject, sex of interrupter, and topic of conversation on the perceptions of interruptions. Perceptual and Motor Skills, 75, 1235-1241.

Dabbs, J. M, Jr., \& Ruback, R. B. (1984). Vocal patterns in male and female groups. Personality and Social Psychology Bulletin, 10, 518-525.

Fisek, M. H., Berger, J., \& Norman, R. Z. (1991). Participation in heterogeneous and homogeneous groups: A theoretical integration. American Journal of Sociology, 97, 114-142.

Floyd, K., Ramirez, A, Jr., \& Burgoon, J. K. (1999). Expectancy violations theory. In L. K. Guerrero, J. A. DeVito, \& M. L. Hecht (Eds.), The nonverbal communication reader (2nd ed., pp. 437-444). Prospect Heights, IL: Waveland Press.

Foschi, M., \& Lapointe, V. (2002). On conditional hypotheses and gender as a status characteristic. Social Psychology Quarterly, 65(2), 146-162.

Hall, J. A. (2006). Nonverbal behavior, status, and gender: How do we understand their relations? Psychology of Women Quarterly, 30(4), 384-391.

Hall, J. A., Coats, E. J., \& Smith LeBeau, L. (2005). Nonverbal behavior and the vertical dimension of social relations: A meta-analysis. Psychological Bulletin, 131, 898-924. 
Henley, N. M. (1977). Body politics: Power, sex, and nonverbal communication. Englewood Cliffs, NJ: Prentice-Hall.

Henley, N. M. (1995). Body politics revisited: What do we know today? In P. J. Kalbfleisch \& M. J. Cody (Eds.), Gender, power, and communication in human relationships (pp. 27-61). Hillsdale, NJ: Erlbaum.

Hopcroft, R. (2002). Is gender still a status characteristic? Current Research in Social Psychology, 7(20), 339-347.

James, D., \& Clarke, S. (1993). Women, men, and interruptions: A critical review. In D. Tannen (Ed.), Gender and conversational interaction (pp. 231-280). New York, NY: Oxford University Press.

Kennedy, C. W., \& Camden, C. (1983). A new look at interruptions. Western Journal of Speech Communication, 47, 45-58.

LaFrance, M. (1992). Gender and interruptions: Individual infraction or violation of the social order? Psychology of Women Quarterly, 16, 497-512.

Lewis, R. J., Derlega, V. J., Shankar, A., Cochard, E., \& Finkel, L. (1997). Nonverbal correlates of confederates' touch: Confounds in touch research. Journal of Social Behavior and Personality, 12, $821-830$.

Malloy, T. E., \& Janowski, C. L. (1992). Perceptions and metaperceptions of leadership: Components, accuracy, and dispositional correlates. Personality and Social Psychology Bulletin, 18, 700-708.

Rashotte, L. S., \& Webster, M, Jr. (2005). Gender status beliefs. Social Science Research, 34(3), 618-633.

Ridgeway, C. L. (1982). Status in groups: The importance of motivation. American Sociological Review, 47, 76-88.

Ridgeway, C. L. (1987). Nonverbal behavior, dominance, and the basis of status in task groups. American Sociological Review, 52, 683-694.

Ridgeway, C. L., \& Berger, J. (1986). Expectations, legitimation, and dominance behavior in task groups. American Sociological Review, 51, 603-617.

Ridgeway, C. L., Berger, J., \& Smith, L. (1985). Nonverbal cues and status: An expectation states approach. American Journal of Sociology, 5, 955-978.

Robinson, L. F., \& Reis, H. T. (1989). The effects of interruption, gender, and status on interpersonal perceptions. Journal of Nonverbal Behavior, 13, 141-153.

Roger, D., \& Nesshoever, W. (1987). Individual differences in dyadic conversational strategies: A further study. British Journal of Social Psychology, 26, 247-255.

Schmid Mast, M. (2002). Dominance as expressed and inferred through speaking time: A meta-analysis. Human Communication Research, 28, 420-450.

Skvoretz, J., \& Fararo, T. J. (1996). Status and participation in task groups: A dynamic network model. American Journal of Sociology, 101, 1366-1414.

Smith-Lovin, L., \& Brody, C. (1989). Interruptions in group discussions: The effects of gender and group composition. American Sociological Review, 54, 424-435.

Tannen, D. (1993). The relativity of linguistic strategies: Rethinking power and solidarity in gender and dominance. In D. Tannen (Ed.), Gender and conversational interaction (pp. 165-188). New York, NY: Oxford University Press.

Wagner, D. G. (1988). Status violations: Toward an expectation states theory of the social control of deviance. In M. Webster Jr. \& M. Foschi (Eds.), Status generalization: New theory and research (pp. 110-122). Stanford, CA: Stanford University Press.

Wagner, D. G., \& Berger, J. (1997). Gender and interpersonal task behaviors: Status expectation accounts. Sociological Perspectives, 40, 1-32.

Webster, M, Jr., \& Driskell, J. E, Jr. (1985). Status generalization. In J. Berger \& M. Zelditch Jr. (Eds.), Status, rewards, and influence: How expectations organize behavior (pp. 108-141). San Francisco, CA: Jossey Bass Inc.

Welsh, P. (1999, January 19). Colleges need higher standards, not high school warranties. USA Today, p. 17A.

West, C., \& Zimmerman, D. H. (1983). Small insults: A study of interruptions in cross-sex conversations between unacquainted persons. In B. Thorne, C. Kramarae, \& N. Henley (Eds.), Language, gender and society (pp. 102-117). Rowley, MA: Newbury House Publishers.

Wiley, M. G., \& Woolley, D. E. (1988). Interruptions among equals: Power plays that fail. Gender and Society, 2, 90-102.

Wood, W., \& Karten, S. J. (1986). Sex differences in interaction style as a product of perceived sex differences in competence. Journal of Personality and Social Psychology, 50, 341-347. 
Copyright of Journal of Nonverbal Behavior is the property of Springer Science \& Business Media B.V. and its content may not be copied or emailed to multiple sites or posted to a listserv without the copyright holder's express written permission. However, users may print, download, or email articles for individual use. 